\title{
The quality of clinical practice guidelines for preoperative care using the AGREE II instrument: a systematic review
}

\author{
Agustín Ciapponi* (D), Elena Tapia-López, Sacha Virgilio and Ariel Bardach (1)
}

\begin{abstract}
Background: Our aim was to summarize and compare relevant recommendations from evidence-based CPGs (EB-CPGs).

Methods: Systematic review of clinical practice guidelines. Data sources: PubMed, EMBase, Cochrane Library, LILACS, Tripdatabase, and additional sources. In July 2017, we searched CPGs that were published in the last 10 years, without language restrictions, in electronic databases, and also searched specific CPG sources, reference lists, and consulted experts. Pairs of independent reviewers selected EB-CPGs and rated their methodological quality using the AGREE-II instrument. We summarized recommendations, its supporting evidence, and strength of recommendations according to the GRADE methodology.

Results: We included 16 EB-CPGs out of 2262 references identified. Only nine of them had searches within the last 5 years and seven used GRADE. The median (percentile 25-75) AGREE-II scores for rigor of development was 49\% (35-76\%) and the domain "applicability" obtained the worst score 16\% (9-31\%). We summarized 31 risk stratification recommendations, 21.6\% of which were supported by high/moderate quality of evidence (41\% of them were strong recommendations), and 16 therapeutic/preventive recommendations, 59\% of which were supported by high/moderate quality of evidence $(75.7 \%$ strong). We found inconsistency in ratings of evidence level. "Guidelines' applicability" and "monitoring" were the most deficient domains. Only half of the EB-CPGs were updated in the past 5 years.

Conclusions: We present many strong recommendations that are ready to be considered for implementation as well as others to be interrupted, and we reveal opportunities to improve guidelines' quality.
\end{abstract}

Keywords: Perioperative care, Clinical practice guidelines, Systematic review, GRADE, AGREE-II

\section{Implication statement}

We identified many risk stratification and therapeutic strong recommendations that can be implemented and other ones usually followed by many anesthesiologists in their daily practice that should be interrupted.

Finally, we described opportunities to improve guidelines' quality.

\footnotetext{
* Correspondence: aciapponi@iecs.org.ar

Instituto de Efectividad Clínica y Sanitaria (IECS-CONICET), Emilio Ravignani 2024 (C1414CPV), Buenos Aires, Argentina
}

\section{Background}

An estimated 313 million major surgical procedures are undertaken every year worldwide [1]. Low- and highincome countries show an estimated rate of major surgery of 295 and 11,110 procedures per 100,000 population per year respectively [1], an enormous disparity for the recommended minimum threshold of 5000 operations per 100,000 people, that is associated with desirable health outcomes. At current rates of surgical and population growth, 6.2 billion people (73\% of the world's population) will be living in countries below the minimum recommended rate of surgical care in 2035 [2].

(c) The Author(s). 2020 Open Access This article is licensed under a Creative Commons Attribution 4.0 International License, which permits use, sharing, adaptation, distribution and reproduction in any medium or format, as long as you give appropriate credit to the original author(s) and the source, provide a link to the Creative Commons licence, and indicate if changes were made. The images or other third party material in this article are included in the article's Creative Commons licence, unless indicated otherwise in a credit line to the material. If material is not included in the article's Creative Commons licence and your intended use is not permitted by statutory regulation or exceeds the permitted use, you will need to obtain permission directly from the copyright holder. To view a copy of this licence, visit http://creativecommons.org/licenses/by/4.0/ The Creative Commons Public Domain Dedication waiver (http://creativecommons.org/publicdomain/zero/1.0/) applies to the data made available in this article, unless otherwise stated in a credit line to the data. 
However, the crude number of patients who receive surgery is increasing, as well as their mean age and the occurrence of comorbidities [3]. Because of the inherent risks of death and complications, surgical safety is a significant public-health concern. As examples, 2.4\% (95\% CI 2.1 to $2.6 \%$ ) of patients undergoing surgery will suffer major cardiac complications [4], and 5\% (95\% CI 4.5 to $5.5 \%)$ will have a perioperative myocardial infarction [5]. In this context, to provide adequate preoperative care is truly mandatory. The first routine preoperative tests started 50 years ago with only a handful of actions and have nowadays expanded to a large set of risk stratification or diagnostic tests to define the preoperative clinical risk categories and also many preventive interventions. Lately, efforts to standardize care have been made, specially through the implementation of clinical practice guidelines (CPGs) with recommendations useful both for health providers and patients [6]. These recommendations usually consider all risks and benefits for a risk stratification or therapeutic procedure to be undertaken, sometimes even including algorithm pathways. The potential benefits, like the safety of care and standardization of procedures, are only as good as the quality of the practice guidelines implemented. Unfortunately, those CPGs not supported by the best evidence might promote inappropriate preoperative testing behaviors, negative both for patients and health systems. For example, false positive results, coming from inappropriate testing, may delay or prevent surgery, thus creating unnecessary stress or harm to patients.

Multiple medical societies and organizations around the world have published preoperative evaluation CPGs; however, many of them are not even based on solid scientific evidence. Additionally, not all of them harness methods like the Grading of Recommendations Assessment, Development, and Evaluation (GRADE) approach, which is one of the soundest system for rating the quality of a body of evidence in systematic reviews and CPGs [7]. GRADE offers a transparent and structured process for developing and presenting evidence summaries and making recommendations [7].

A systematic review found no evidence from high quality studies to support routine preoperative tests in healthy adults undergoing non-cardiac surgery [8]. Risk stratification testing based on the problems identified during the preoperative assessment seems justified, but there is still little evidence supporting it [8]. In this way, the implementation of EB-CPGs may lead to a reduction in the number of unnecessary preoperative tests, without affecting patient safety [9-13]. The first health technology assessment (HTA) on the topic published in 1989 by the Swedish Council on Technology Assessment in Health Care (SBU) [14], showed healthcare quality improvements and cost savings using an evidence-based approach. The findings of this report have been confirmed by nine other subsequent studies from five countries, collected in another HTA document [15].

For this reason, through an overview of clinical practice guidelines, we aimed to identify and synthetize EB-CPGs on preoperative care that were published worldwide in the last 10 years, in order to help prioritization processes. We also rated CPGs' quality and summarized recommendations describing their level of evidence and the strength of recommendations according to the GRADE approach [7].

\section{Methods}

Study design We performed a systematic review (overview) of EB-CPGs following Cochrane methods [16] and the Argentinean Academy of Medicine's Guide for the adaptation of CPGs for searching and selecting CPGs [17]. For reporting, we followed the PRISMA statement [18] and a specific guideline for overviews of systematic reviews (Online supplemental material. Appendix 1. PRISMA checklist) [19]. The protocol is available in Spanish including a summary in English. ${ }^{1}$

We aimed to identify the most reliable CPGs; therefore, we used a definition for EB-CPGs previously reported [20]. The inclusion eligibility criteria (all criteria required) were as follows:

a) CPGs of perioperative care published in the last 10 years including those recommendations potentially applicable to any kind of surgery, not site or condition-specific

b) b) Provides a list of the CPG development panel members including their expertise or qualifications.

c) Use standard methods such as Cochrane methods, Equator Network-proposed checklists, or any sufficiently detailed method allowing reproducibility of the identification, data collection, and study risk of bias assessment.

d) Report of the level of evidence that supports each recommendation

Exclusion criteria (any criterion required) were as follows:

a) Guidelines limited to single specific conditions such as obesity, renal disorders, or pheochromocytoma

b) Guidelines limited to single specific body part surgeries such as neurosurgery or colorectal surgery.

${ }^{1}$ https://www.iecs.org.ar/wp-content/uploads/Protocolo-de-Overviewy-adaptaci\%C3\%B3n-de-GPC-prequir\%C3\%BArgicas-1.pdf 
c) Guidelines including some recommendations but whose entire focus was clearly not the preoperative care

Search strategy In July 2017, we searched CPGs published in the last 10 years without language limitations in main electronic databases, metasearch engines, specific CPG sources, reference lists and consultation of experts, and the main scientific societies related to preoperative evaluation. The sources included PubMed, EMBase, Cochrane Library, LILACS, Tripdatabase, and additional sources: National Guideline Clearinghouse, NeLH Guidelines Finder, Guía Salud GPCs en España, GAC guidelines, CMA Infobase: Clinical Practice Guidelines Database (CPGs), New Zealand Guidelines, Scottish Clinical Guidelines, EBM Guidelines, Health Services/Technology Assessment Text (HSTAT), National Institute for Health and Clinical Excellence (NICE), and Institute for Clinical Systems Improvement (ICSI). See Online supplemental material. Appendix 2. Search strategy for details of these sources and our search strategy for preoperative care. The search strategy was developed by a trained librarian, and the citations were initially managed for deduplication trough EndNote $9^{\circ}$ reference manager.

Selection and data extraction Pair of reviewers independently selected (by title and abstract first, and full text eligible studies afterwards) the articles retrieved, with a specific software to facilitate the initial phases of systematic reviews called Early Review Organizing Software (EROS) [21]. One reviewer extracted them while the other verified the data in a previously piloted form (which included variables such as search date, objective, setting, target population, target professionals, recommendations, classification system of the quality of evidence and of the strength of the recommendation, quality of evidence by recommendation, and the strength of each recommendation) and preoperative clinical risk criteria and categories (see Online supplemental material 3. Preoperative clinical risk criteria and categories). Discrepancies were resolved by a consensus of the whole team.

Guideline quality appraisal and classification Independent pairs of reviewers rated each EB-CPGs using the AGREE-II tool consisting of 23 key items organized in six domains: scope and purpose, stakeholder involvement, rigor of development, clarity of presentation, applicability, editorial independence, and two overall evaluation items [22]. Each item was graded using a scale of 7 points: from 1, meaning "Strongly disagree," to 7, meaning "Strongly agree." The total was presented as a percentage of the maximum possible score for that domain (from 0 to $100 \%$ ). We present the AGREE-II domain scores expressed as a percentage across
CPGs (Online Supplemental material. Appendix 5 with the explanation of each items of the AGREE-II domains). Discrepancies were resolved by a consensus of the whole team.

We also categorized each EB-CPGs according to the extent to which they successfully addressed AGREE-II criteria as follows [17]:

Strongly recommended (++), CPG whose standardized score exceeds $60 \%$ in $\geq 4$ AGREE-II domains. The scores of the remaining domains must be $\geq 30 \%$ and > $60 \%$ for the domain rigor of development.

Recommended (+), CPG whose standardized score ranges from 30 to $60 \%$ in $\geq 4$ AGREE-II domains. The rigor of development score must be between 30 and $60 \%$. Not recommended (-), CPG whose standardized score is $<30 \%$ in $\geq 4$ AGREE-II domains or if rigor of development score is less than $30 \%$.

To deal with discrepancies between the direction and strength of the CPG recommendations, we applied a rule to decide "doing or not doing the recommendation":

Yes $(\mathrm{Y})-$ no $(\mathrm{N})$ to doing it: $\geq 2 / 3$ recommendations in the same direction (for/against) and $\geq 2 / 3$ strong recommendations.

Probably yes (PY)-probably no (PN) to doing it: $\geq 2 / 3$ recommendations in the same direction (for/against) and $<2 / 3$ strong recommendations.

Uncertainty (?) to do it: $<2 / 3$ recommendations in the same direction (for/against).

Synthesis of results We conducted a tabular synthesis of the recommendations to describe their strength and the level of evidence supporting them according to the current GRADE methodology [7], and transforming the original grading system when necessary, to compare and integrate the results for each recommendation in a unified manner. Simply put, the GRADE quality of evidence can be HIGH, MODERATE, LOW and VERY LOW. The Randomized Clinical Trials (RCTs) start from HIGH quality of evidence, and the non-randomized studies start from a LOW quality of evidence. Five criteria can downgrade one or two levels: methodological quality (study limitations), inconsistency of results, indirectness, imprecision, and publication bias. In cases where there are no methodological limitations, there are three criteria that can upgrade one or two levels: magnitude of effect, dose-response effect, and confounders underestimating the effect. For mapping the level of evidence to a common grading system (GRADE), we reassessed all evidence when the translation was not obvious. Pair of reviewers independently extracted or reassessed the level of evidence, and discrepancies were resolved by a consensus of the whole team. Regarding 
the strength of a recommendation, which is defined as the extent to which one can be confident that the desirable consequences of an intervention outweigh its undesirable consequences, GRADE uses four simple categories to classify them. The categories are "strong" or "weak" and "for" or "against" a certain risk stratification or therapeutic approach. We presented descriptive statistics as percentages or means with standard deviations.

\section{Results}

\section{Search results}

The search strategy identified 2262 references after the elimination of duplicates. After the selection process, we identified 23 references corresponding to 16 EB-CPGs published in the last 10 years (Fig. 1 flowchart). Two references were examined in depth and eventually excluded since they only transcribed pre-existing CPGs, already included in our selection [23, 24].

\section{Guideline characteristics}

Table 1 provides a general description of the included EBCPGs. Seven were developed in America (4 in the USA, 1 in Argentina, 1 in Brazil, and 1 in Canada), seven in Europe (2 continental, 2 from Italy, 1 in Belgium, 1 in Scotland, and 1 in UK), and two were global collaborations. Only 8/16 (50\%) of the EB-CPGs that reported their search date, conducted their searches within the last 5 years. Out of the EB-CPGs, ten addressed multiple practices, five focused on unique practices, one referred to perioperative fasting, and the remaining four were about antimicrobial prophylaxis. Furthermore, four were risk stratification recommendations, five were therapeutic or preventive interventions, and six considered both aspects.

Each guideline reports the levels of evidence and the recommendation grading systems used by their authors. The grading system used were GRADE (7 EB-CPGs), SIGN [41] (2 EB-CPGs), and the others utilized their own or modified systems (Online supplemental material Appendix 4).

We presented the scores as a percentage per each AGREE-II domain. The domains with the best median score (percentile 25-75) were editorial independence $91 \%$ (81-100), clarity of presentation $85 \%$ (69-97), and scope and objective $80 \%$ (65-89). Stakeholder involvement 53\% (44-62) and rigor of development 49\% (3576) had an intermediate performance while "applicability" was the most deficient 16\% (9-31). Regarding the guideline recommendation category, 6/16 (37\%) were classified as highly recommended and the rest as recommended (Online supplemental material Appendix 5). An overall AGREE-II score is also presented in Table 1.

\section{Risk stratification recommendations (diagnostic tests)}

Table 2 shows the risk stratification recommendations presenting the level of evidence and recommendation strength of the EB-CPG with the highest overall and methodological rigor AGREE-II score. The 31 risk stratification recommendations included 102 specific

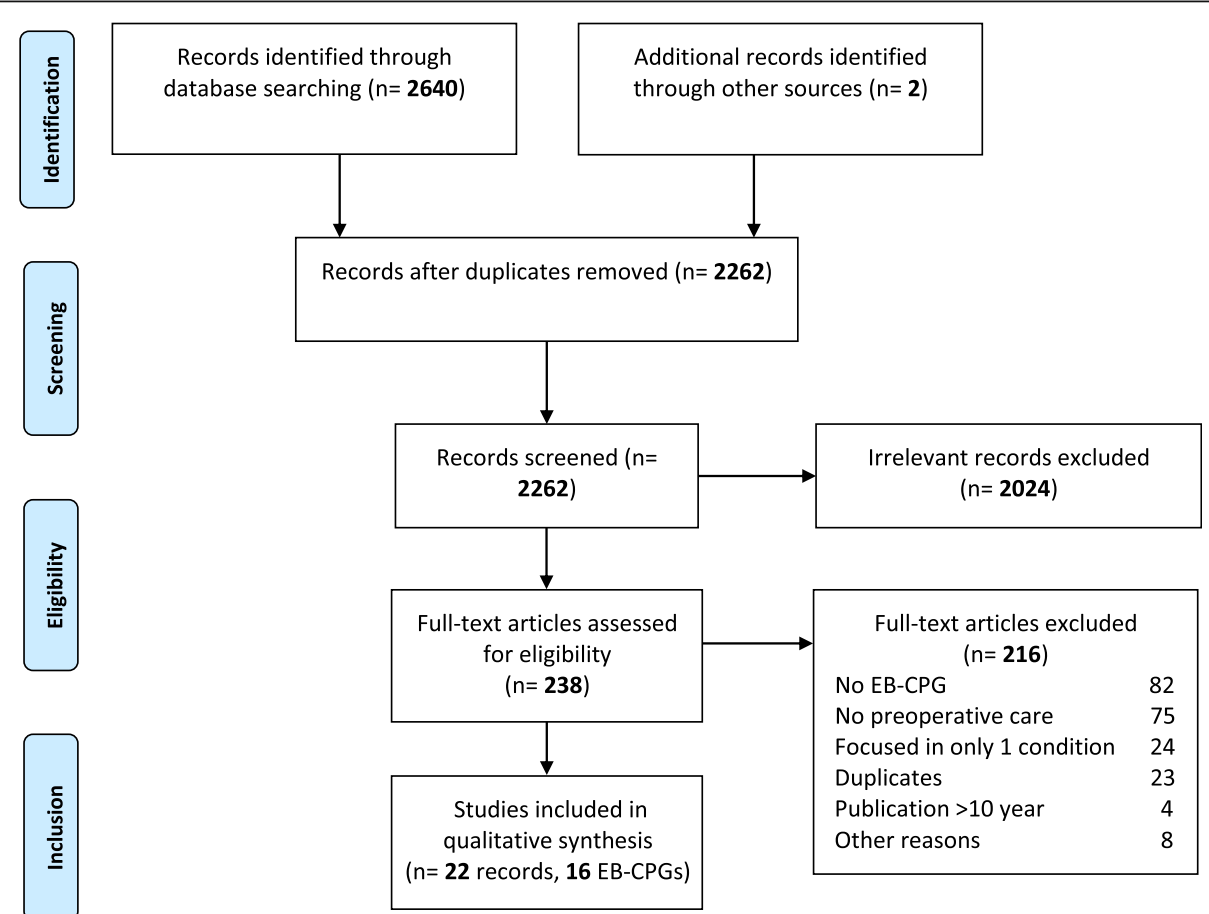

Fig. 1 Study flowchart 
Table 1 General description of the EB-CPGs included

\begin{tabular}{|c|c|c|c|c|c|c|c|}
\hline \multicolumn{3}{|l|}{ Development entity } & \multirow{2}{*}{$\begin{array}{l}\text { Literature } \\
\text { search year }\end{array}$} & \multirow[t]{2}{*}{ Title } & \multirow{2}{*}{$\begin{array}{l}\text { Single or } \\
\text { multiple } \\
\text { practice }\end{array}$} & \multirow{2}{*}{$\begin{array}{l}\text { Type of } \\
\text { practice } \\
\text { evaluated* }\end{array}$} & \multirow{2}{*}{$\begin{array}{l}\text { \$Guide } \\
\text { Quality } \\
1=\text { lowest } \\
7=\text { highest }\end{array}$} \\
\hline $\begin{array}{l}\text { Acronym—guide } \\
\text { publication year }\end{array}$ & Full name & Location & & & & & \\
\hline NICE 2016 [25] & $\begin{array}{l}\text { National Institute of } \\
\text { Health and Care of } \\
\text { Excellence }\end{array}$ & UK & 2015 & $\begin{array}{l}\text { Clinical Guidelines. } \\
\text { Preoperative tests } \\
\text { (update): routine } \\
\text { preoperative tests for } \\
\text { elective surgery }\end{array}$ & 6 & Dx & 6 \\
\hline ESC/ESA 2014 [26] & $\begin{array}{l}\text { European Society of } \\
\text { Cardiology/European } \\
\text { Society of Anesthesia }\end{array}$ & Europe $^{+}$ & 2014 & $\begin{array}{l}\text { ESC/ESA Guidelines on } \\
\text { non-cardiac surgery: } \\
\text { cardiovascular assessment } \\
\text { and management }\end{array}$ & 4.5 & $D x, T x$ & 4.5 \\
\hline SBC 2017 [27] & $\begin{array}{l}\text { Brazilian Society of } \\
\text { Cardiology }\end{array}$ & Brazil & 2016 & $\begin{array}{l}\text { 3rd guide for the perioperative } \\
\text { evaluation of the Brazilian Society } \\
\text { of Cardiology }\end{array}$ & 4.5 & $D x, T x$ & 4.5 \\
\hline ACC/AHA 2014 [28] & $\begin{array}{l}\text { American College of } \\
\text { Cardiology/American } \\
\text { Heart Association }\end{array}$ & USA & 2013 & $\begin{array}{l}\text { ACC/AHA guideline on } \\
\text { perioperative cardiovascular } \\
\text { evaluation and management } \\
\text { of patients undergoing } \\
\text { noncardiac surgery }\end{array}$ & 6 & Dx & 6 \\
\hline CCSG 2017 [29] & $\begin{array}{l}\text { Canadian Cardiovascular } \\
\text { Society }\end{array}$ & Canada & 2015 & $\begin{array}{l}\text { Guidelines on perioperative } \\
\text { cardiac risk assessment and } \\
\text { management for patients who } \\
\text { undergo noncardiac surgery }\end{array}$ & 3 & $D x, T x$ & 3 \\
\hline ERAS Society 2012 [30] & $\begin{array}{l}\text { Society of post-surgical } \\
\text { recovery }\end{array}$ & World & 2012 & $\begin{array}{l}\text { Guidelines for perioperative care } \\
\text { in elective rectal/pelvic surgery: } \\
\text { enhanced recovery after surgery }\end{array}$ & 4 & $D x, T x$ & 4 \\
\hline SARNePI 2014 [31] & $\begin{array}{l}\text { Italian Society of Anesthesia } \\
\text { and Intensive Pediatric } \\
\text { Therapy and Neonatology }\end{array}$ & Italy & 2012 & $\begin{array}{l}\text { Preoperative evaluation in } \\
\text { infants and children: } \\
\text { recommendations } \\
\text { of the Italian Society of } \\
\text { Pediatric and Neonatal } \\
\text { Anesthesia and Intensive } \\
\text { Care (SARNePI). }\end{array}$ & 4 & Dx & 4 \\
\hline ICSI 2012 [32] & $\begin{array}{l}\text { Institute for the } \\
\text { Improvement of } \\
\text { Clinical Systems }\end{array}$ & USA & 2012 & Pre-operative evaluation & 4 & $D x, T x$ & 4 \\
\hline ERAS Society 2016 [33] & $\begin{array}{l}\text { Post-Surgical } \\
\text { Recovery Society }\end{array}$ & World & 2014 & $\begin{array}{l}\text { Guidelines for pre- and intra- } \\
\text { operative care in gynecologic/ } \\
\text { oncology surgery: enhanced } \\
\text { recovery after surgery }\end{array}$ & 4 & $D x, T x$ & 4 \\
\hline ESA 2011 [34] & $\begin{array}{l}\text { European Society } \\
\text { of Anesthesia }\end{array}$ & Europe $^{+}$ & 2009 & $\begin{array}{l}\text { Perioperative fasting guide in } \\
\text { adults and children }\end{array}$ & 4 & Tx & 4 \\
\hline BARA 2013 [35] & $\begin{array}{l}\text { Regional Anesthesia } \\
\text { Associations of Belgium }\end{array}$ & Belgium & NR & $\begin{array}{l}\text { Recommendations and } \\
\text { guidelines for obstetric } \\
\text { anesthesia in Belgium }\end{array}$ & 3 & Dx & 3 \\
\hline ASHP 2013 [36] & $\begin{array}{l}\text { American Society of } \\
\text { Health-System Pharmacists }\end{array}$ & USA & 2010 & $\begin{array}{l}\text { Clinical practice guidelines } \\
\text { for antimicrobial prophylaxis } \\
\text { in surgery }\end{array}$ & 5.5 & Tx & 5.5 \\
\hline SIGN 2014 [37] & $\begin{array}{l}\text { Scottish Intercollegiate } \\
\text { Guidelines Network }\end{array}$ & Scotland & 2007 & $\begin{array}{l}\text { Antimicrobial prophylaxis in } \\
\text { surgery }\end{array}$ & 6.5 & Tx & 6.5 \\
\hline CDC 2017 [38] & $\begin{array}{l}\text { Center for Disease } \\
\text { Control }\end{array}$ & USA & 2014 & $\begin{array}{l}\text { Guideline for the prevention } \\
\text { of surgical site infections }\end{array}$ & 6 & Tx & 6 \\
\hline PNLG 2009 [39] & $\begin{array}{l}\text { National Program of } \\
\text { Italian Guides }\end{array}$ & Italy & $N R$ & $\begin{array}{l}\text { Perioperative antibiotic } \\
\text { prophylaxis in adults }\end{array}$ & 3 & Tx & 3 \\
\hline SAC 2016 [40] & $\begin{array}{l}\text { Argentine Society of } \\
\text { Cardiology }\end{array}$ & Argentina & 2015 & $\begin{array}{l}\text { Argentine Consensus on } \\
\text { Cardiovascular Risk Assessment } \\
\text { in Non-Cardiac Surgery }\end{array}$ & 6 & $D x, T x$ & 6 \\
\hline
\end{tabular}

NR not reported

*Diagnostic practice (Dx), therapeutic/preventive (Tx)

${ }^{\S}$ Based on AGREE-II tool. See supplemental materials for more details

${ }^{\dagger}$ The whole continent 
Table 2 Risk stratification, GRADE level of evidence and strength of recommendation by clinical specialties

\section{General requirements}

\section{Preoperative evaluation}

Pediatric patients receiving anesthesia

Very low

Strong for

Emergency surgeries in pediatric patients

Very low

Strong against

All patients who are undergoing diagnostic or therapeutic procedures

very low

Weak for

Patients with ASA 1 or 2 without surgical or obstetric history (preanesthetic evaluation, including

Very low

Weak for

physical examination, the day of the procedure).

Patient with significant medical, surgical, or obstetrical history (anesthesiologist assessment)

In case of bleeding or complication history of previous alloimmunization, it is recommended to evaluate the blood type.

Very low

Weak for

Very low

Weak for

2. Informed consent (Ideally written)

Provide information on risks and benefits related to obstetric anesthesia and analgesia.

Very low

Weak for

\section{Complete laboratory}

Patients undergoing low-risk surgery independently of their ASA score

Very low

Strong against

Patients undergoing intermediate-risk surgery

Patients with renal or cardiovascular disease undergoing intermediate-risk surgery that has not been recently evaluated

Patients undergoing high-risk surgery

Patients with preeclampsia or other preceding or a suspect of hemostatic disorder, it is recommended to apply platelet count, liver function test, and evaluation of coagulation

In case of bleeding or complication history of previous alloimmunization, it is recommended

to evaluate the blood type.

Very low

Strong against

Very low

Weak for

Patients with liver failure

In anticoagulated patients (e.g., consume Warfarin)

Patients with potential risk of bleeding undergoing intermediate or high-risk surgery

Routinely

$\begin{array}{ll}\begin{array}{ll}\text { Very low } \\ \text { Very low }\end{array} & \begin{array}{l}\text { Strong for } \\ \text { Weak for }\end{array} \\ \text { Very low } & \text { Weak for } \\ \text { Very low } & \text { Strong for } \\ \text { Low } & \text { Strong for } \\ \text { Very low } & \text { Strong for } \\ \text { Very low } & \text { Strong against }\end{array}$

\section{Hematocrit and hemoglobin}

In pediatric patients with possible bleeding

In pediatric patients routinely perform minor surgery

Patients with anemia or blood disease or liver disease; when you suspected of anemia or other chronic disease during clinical examination. In medium or high-risk surgeries, anticipated

\section{Hemostasis/coagulation tests}

Pediatric patients with negative history

Patients with a history of bleeding

Patients with liver failure

In anticoagulated patients (e.g., consume Warfarin)

Patients with potential risk of bleeding undergoing intermediate or high-risk surgery

Routinely

\section{Urinalysis}

Routinely before surgery

Urine or culture if diagnosing a urinary infection can influence surgery decisions

\section{Glucose}

Routinely to pediatric patients 
Table 2 Risk stratification, GRADE level of evidence and strength of recommendation by clinical specialties (Continued)

\section{Glycated hemoglobin (HbA1c) test}

Diabetic patient without $\mathrm{Hb} 1 \mathrm{Ac}$ within 3 months

Patients without diabetes

\section{Assessment of risk factors for surgical site infection}

Assessment of smoking, diabetes, obesity, malnutrition, and chronic skin disease

\section{Kidney function tests}

For minor surgery in ASA $1 / 2$ patients or intermediate-risk surgery in ASA 2 patients

For complex or major surgery in ASA 1 patients at risk of acute kidney injury (AKI)

In intermediate-risk surgery in ASA 2 patients at risk of AKI. In patients with increased risk surgery performed

ASA 3/4 patients: at risk of AKI in low-risk surgery or just higher-risk surgery

\section{Sickle cell disease/trait test}

Routinely

Assess personal of family history of sickle cell anemia

Contact a specialized service providing treatment to a confirmed case

\section{Chest X-ray}

Routinely in healthy people

Patients with a history or diagnostic tests suggesting cardiorespiratory disease

Patients over 40 years, patients undergoing non-low-risk surgery

Patients undergoing non-low-risk surgery or mainly intrathoracic or intraabdominal surgery

\section{Pregnancy testing}

Performed in women of childbearing age

Test the day of surgery in women of childbearing age.

In pregnant women, ensure that surgery and anesthesia does not threaten the fetus life.

Document all discussions with women about whether to carry out a pregnancy test.

Carry out the pregnancy test under the possibility of pregnancy.

\section{Cardiovascular requirements}

\section{Electrocardiography:}

In neonates and/or children of 6 months

Healthy people undergoing minor surgery

Perform in cases of clinical suspicion

People over 65 undergoing minor or intermediate surgery

People with cardiovascular disease

People with a morbidity undergoing intermediate or major surgery

\section{Effort electrocardiography}

Patients undergoing surgeries of intermediate or high risk of complications, including arterial vascular surgery (without severe cardiovascular perioperative conditions)

Patients undergoing low-risk surgery

Patients undergoing intermediate-risk surgery

16. Resting echocardiography

\section{High-risk surgery}

Patient with suspected moderate or severe valvular involvement without evaluation in the last year or with worsening of symptoms

Patient with heart failure or symptoms suggestive of heart problems, without assessment in the past year, undergoing cardiac surgery

Symptomatic patients with stent grafts who go to surgery and who have no evaluation in the last year

Asymptomatic patients

$\begin{array}{ll}\text { Very low } & \text { Weak for } \\ \text { Very low } & \text { Weak against } \\ \text { Low } & \text { Strong for } \\ \text { Very low } & \text { Weak against } \\ \text { Very low } & \text { Weak for } \\ \text { Very low } & \text { Weak for } \\ \text { Very low } & \text { Weak for } \\ \text { Very low } & \text { Weak against } \\ \text { Very low } & \text { Weak against } \\ \text { Very low } & \text { Weak for } \\ \text { Low } & \text { Strong against } \\ \text { Moderate } & \text { Weak for } \\ \text { Low } & \text { Weak for } \\ \text { Moderate } & \text { Weak for } \\ \text { Very low } & \text { Weak for } \\ \end{array}$


Table 2 Risk stratification, GRADE level of evidence and strength of recommendation by clinical specialties (Continued)

Low, intermediate or uncertain surgical risk

Routine test in asymptomatic patients without suspect of heart failure or severe valvular disease

\section{Effort echocardiography}

Routinely to assess cardiac risk

\section{Tomographic coronary angiography}

Routinely to assess cardiac risk

\section{Assessment of left ventricular function}

Patients suspected to have valvular disease with important clinical manifestations or undergoing liver transplantation

Patients with heart failure without ventricular function assessment

Patients undergoing high-risk surgery

Obese patients (BMI $\geq 40)$ undergoing bariatric surgery

Routinely

\section{Natriuretic peptide}

Patients undergoing cardiac surgery

Patients over 55 years with at least one cardiovascular risk factor undergoing non-cardiac surgery

\section{Brain natriuretic peptide (BNP) or NT-proBNP}

Patients over 65 years or patients between 45 and 64 years with significant cardiovascular disease or score (revised cardiac risk index $(\mathrm{RCRI}) \geq 1$

\section{Troponin}

Troponin prior to vascular surgery

Troponin as a preoperative marker of cardiovascular risk and mortality in non-cardiac surgery

\section{Coronary angiography}

The indications of angiography and coronary revascularization are those of non-surgical context

Urgent angiography in patients with myocardial infarction without ST elevation requiring elective non-cardiac surgery or with a computed tomography $(C T)$ with multiple cuts showing serious injury of the left coronary trunk

Urgent or early invasive strategy for patients with NSTEMI requiring elective non-cardiac surgery

Patients with recent coronary disease at high clinical risk, functional class III-IV in the last 6 months, or patients with severe valve disease and concomitant coronary heart disease

Patients with non-high-risk criteria (Annex 5) and functional or pharmacological stress tests showing myocardial ischemia

Patients with or without stable coronary disease functional class I-II without evidence of ischemia by stress tests, or those with severe coronary disease according $C T$ multislice (excluding injury of left coronary trunk) clinically stable without ischemia, or in patients whose non-cardiac surgery cannot be delayed more than 2 weeks due to the underlying disease

\section{Noninvasive test for myocardial ischemia}

Patients undergoing intermediate or high-risk surgery (without severe cardiovascular perioperative conditions) and those undergoing arterial vascular surgery

Intermediate or high-risk patients with poor functional capacity undergoing intermediate-risk surgery

Patients undergoing low-risk surgery

Low-risk patients undergoing low or intermediate-risk surgery

\section{Pulmonary requirements}

\section{Polysomnography}

In patients requiring continuous positive airway pressure (CPAP)

Patients presumed to have obstructive sleep apnea (OSA) based on the preoperative history and physical examination

\section{Lung function tests}

Spirometry in patients undergoing non-high-risk surgery
Very low

Weak against

Low

Strong against

Moderate

Strong against

Low

Weak for

Low

Weak against

Moderate

Weak for

Low

Weak for

Moderate

Strong against

High

Weak for

Low

Weak for

Moderate

Strong for

Moderate

Weak for

Low

Weak for

Moderate

Strong for

Low

Weak for

High

Strong for

Low

Strong for

Low

Weak against

Low

Strong against
High

Low

Very low 
Table 2 Risk stratification, GRADE level of evidence and strength of recommendation by clinical specialties (Continued)

\begin{tabular}{lc}
\hline Arterial blood gas analysis in patients undergoing non-high-risk surgery & Very low \\
Assessment by medical senior anesthesiologist after confirming respiratory illness or suspected & Very low \\
in patients ASA 3/4 undergoing high-risk surgery & Weak for
\end{tabular}

\section{High risk surgery requirements}

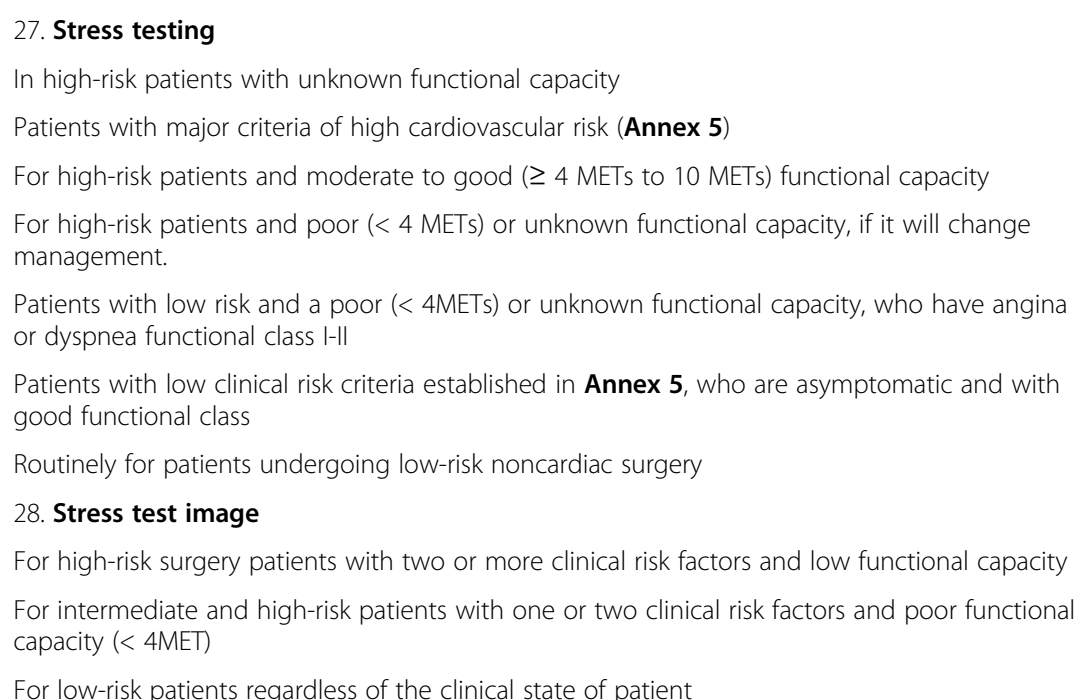

For low-risk patients regardless of the clinical state of patient

\begin{tabular}{|c|c|}
\hline Moderate & Weak against \\
\hline Low & Strong against \\
\hline Low & Weak against \\
\hline Low & Weak against \\
\hline Low & Weak for \\
\hline Low & Weak against \\
\hline Moderate & Strong against \\
\hline Low & Strong for \\
\hline Very Low & Weak against \\
\hline Very low & Strong against \\
\hline
\end{tabular}

\section{Special situations or considerations}

29. Cardiopulmonary stress test

Cardiopulmonary exercise testing to improve the estimation of cardiac risk

High-risk patients with unknown functional capacity
Low

Moderate

Moderate

Moderate

High

Moderate

Moderate
Strong against

Weak against

Weak for

Strong against

\section{Prokinetic and other interventions}

Routine use of antacids, metoclopramide, or $\mathrm{H} 2$-receptor antagonists before elective surgery in non-obstetric patients

H2-receptor antagonists the night before and the morning of elective cesarean section

Intravenous H2-receptor antagonist before emergency cesarean section; supplemented with $30 \mathrm{ml}$ of sodium citrate if general anesthesia is planned

The presented level of evidence and recommendation strength comes from the EB-CPG with the highest overall and methodological rigor AGREE-II score. The level of evidence and recommendation strength by EB-CPG is presented in the online supplemental material $6 . a$

recommendations according to the population/problem or the type of surgery. Out of the 102 recommendations, $5(4.9 \%)$ had a high level of evidence, $17(16.7 \%)$ had a moderate level, $45(44.1 \%)$ had a low level, and $35(34.3 \%)$ had a very low/insufficient level. Regarding recommendation strength, 24 (23.5\%) were strong for, 26 (25.5\%) were strong against, 37 (36.3\%) weak for, and 15 (14.7\%) were weak against.

We found discrepancies among EB-CPG in 10 out of $102(10 \%)$ risk stratification recommendations After applying the rule "doing or not doing the recommendation," 31 (60 specific) are "doing" and 31 are (39 specific) "not doing" diagnostic evaluations (see Online supplemental material Appendix 6. Table 1 GRADE level of evidence and strength of recommendations by CPG; Table 2 Recommended risk stratification evaluations only and Table 3 Not recommended risk stratification evaluations to facilitate the finding of relevant recommendation by different point of access).

\section{Therapeutic/preventive recommendations}

Table 3 shows the therapeutic/preventive recommendations using the same presenting criterion in Table 2 . The 16 therapeutic/preventive recommendations included 78 specific recommendations according to the 
Table 3 Therapeutic/preventive care, GRADE level of evidence and strength of recommendation*

Recommendation

Level of

evidence

\section{General recommendations}

\section{Smoking cessation}

Smoking cessation advice

2. Fast

Stop fluid intake in children and adults at least $2 \mathrm{~h}$ before elective surgery in

Stop intake of solids in children and adults $6 \mathrm{~h}$ before surgery

Stop intake in infants up to $4 \mathrm{~h}$ before surgery and $6 \mathrm{~h}$ in those who consume other milk

Intake of clear fluids (including water, clear juice, and tea or coffee without milk) in children and adults up to $2 \mathrm{~h}$ before elective surgery.

\section{Carbohydrate intake}

Intake until $2 \mathrm{~h}$ before surgery in nondiabetics

Taking high carbohydrate drinks to $2 \mathrm{~h}$ before elective surgery even in diabetic patients

Drinking liquids rich in carbohydrates before elective surgery improves subjective well-being, reduces thirst and hunger and reduces postoperative insulin resistance

\section{Alcohol intake}

Avoid drinking 4 weeks before, especially in rectal surgery.

\section{Bowel preparation (cleansing)}

With or without planned bowel resection

6. Antimicrobial prophylaxis (see Annex $\mathbf{2}$ for specific antibiotic recommendation details)

Antibiotics intravenous (first generation cephalosporin or amoxicillin/clavulanate) routinely $60 \mathrm{~min}$ before the incision. Further doses for prolonged surgery, severe blood losses and obese patients

Vancomycin monotherapy

For insertion of a pacemaker or cardiac defibrillator, in open surgery including coronary bypass and valve prosthesis placement

For lung resection

For clean-contaminated head and neck surgery

For adenotonsillectomy

For ear surgery including myringoplasty

For nasal and paranasal sinus surgeries

For clean head and neck surgery

For colorectal surgery

For oncological breast surgery and reduction mammoplasty

For endoscopic gastrostomy and stomach and duodenum surgery

For clean-contaminated procedures esophagus and small intestine

For appendectomy, open biliary surgery, liver resection surgery, pancreatic surgery, breast augmentation

For inguinal hernia repair with or without use of prosthetic material, laparoscopic hernia surgery with or without prosthetic material, diagnostic laparoscopy and excisional lymph node biopsy

For laparoscopic cholecystectomy surgery

Intranasal mupirocin in adult patients undergoing surgery with a high risk of major morbidity due to S. aureus or MRSA

For craniotomy and cerebrospinal flow deviation

For induction of abortion and cesarean section

For abdominal and vaginal hysterectomy

For salpingo-oophorectomy and ovarian tissue excision or reconstruction

For ankle prosthesis implantation

For knee prosthesis implantation
Low

Moderate

Moderate

Low

Moderate

Moderate

High

High

Moderate

Moderate

Low

Low

High

Moderate

High

High

High

Moderate

very low

High

High

Moderate

very low

High

High

High

High

High

High

Moderate

High

High

Low
Strong for

Strong for

Strong for

Strong for

Strong against

Strength of

recommendation

\section{r}

Weak for

Weak against

Strong for

Strong for

Strong for

Weak against

Strong against

Strong against

Strong against

Strong for

Strong for

Strong for

Weak for

Strong for

Strong against

Strong against

Strong for

Strong for

Strong for

Strong for

Strong against

Strong for

Strong for 
Table 3 Therapeutic/preventive care, GRADE level of evidence and strength of recommendation* (Continued)

\begin{tabular}{|c|c|c|}
\hline Recommendation & $\begin{array}{l}\text { Level of } \\
\text { evidence }\end{array}$ & $\begin{array}{l}\text { Strength of } \\
\text { recommendation }\end{array}$ \\
\hline $\begin{array}{l}\text { For closed fracture fixation, mounting a prosthetic device when there is no direct evidence } \\
\text { available, ankle fracture repair }\end{array}$ & High & Strong for \\
\hline For spinal surgery & Moderate & Strong for \\
\hline For elective orthopedic surgeries without use of prosthesis & Very low & Strong against \\
\hline For transurethral resection of the prostate, lithotripsy & High & Strong for \\
\hline $\begin{array}{l}\text { For transrectal prostate biopsy, radical prostatectomy, radical cystectomy, surgery of renal } \\
\text { parenchyma, nephrectomy and removal of hydrocele }\end{array}$ & Moderate & Strong for \\
\hline For transurethral resection of bladder tumors & Very low & Strong against \\
\hline For lower limb amputation and arterial surgery in the abdomen or lower extremities & Moderate & Strong for \\
\hline $\begin{array}{l}\text { For carotidal thromboendarterectomy, endarterectomy, tubal surgery varicose veins and other } \\
\text { venous occlusions }\end{array}$ & Very low & Strong against \\
\hline Antibiotic must have a spectrum of action against likely contaminants & Very low & Weak for \\
\hline $\begin{array}{l}\text { Avoid beta-lactam antibiotics in patients with a history of anaphylaxis, urticaria, or rash } \\
\text { appearing immediately after treatment with penicillin }\end{array}$ & Low & Weak for \\
\hline $\begin{array}{l}\text { Antibiotic prophylaxis should begin immediately before anesthesia and, in any case, of } 30 \text { to } \\
60 \text { min before the first skin incision }\end{array}$ & High & Strong for \\
\hline More than single antibiotic dose (except in special situations) & Very low & Strong against \\
\hline $\begin{array}{l}\text { Additional intraoperative dose of antibiotic in adults, to be held after the fluid replenishment, if a } \\
\text { loss of more than } 1500 \mathrm{ml} \text { of blood is verified during the operation or after hemodilution of } \\
\text { more } 15 \mathrm{ml} \text { per } \mathrm{kg}\end{array}$ & Very low & Weak for \\
\hline $\begin{array}{l}\text { Consider the increased risk clostridium difficile infection associated with some antibiotics like } \\
\text { cephalosporins, clindamycin, fluoroquinolones, carbapenems }\end{array}$ & Low & Weak for \\
\hline Consider glycopeptides for prophylaxis in patients undergoing high-risk surgery that are positive for MRSA & High & Strong for \\
\hline $\begin{array}{l}\text { Registering a minimum set of data on medical history and treatment forms to assess the suitability } \\
\text { of perioperative antibiotic prophylaxis }\end{array}$ & Very low & Strong for \\
\hline \multicolumn{3}{|l|}{ 7. Preanesthetic medication } \\
\hline Benzodiazepines & Moderate & Weak against \\
\hline \multicolumn{3}{|l|}{ 8. Thromboprophylaxis } \\
\hline Compression stockings & High & Strong for \\
\hline \multicolumn{3}{|l|}{ Low molecular weight heparin } \\
\hline \multicolumn{3}{|l|}{ Continuation of contraceptives } \\
\hline \multicolumn{3}{|l|}{ 9. Surgical site preparation } \\
\hline Alcohol-chlorhexidine use & High & Strong for \\
\hline Antimicrobial agents (i.e., ointments, solutions, or powders) for prevention of surgical site infection & Low & Strong against \\
\hline Hair clipping & High & Strong for \\
\hline Adhesive strips of plastic with or without antimicrobial properties & Moderate & Weak against \\
\hline Microbial sealant after intraoperative skin preparation & Low & Weak against \\
\hline Patients bath with antiseptic agent at least one night before surgery & Moderate & Strong for \\
\hline \multicolumn{3}{|l|}{ 10. Prokinetic } \\
\hline For obstetrical patients & Moderate & Strong for \\
\hline For non-obstetrical patients & Moderate & Strong against \\
\hline
\end{tabular}

Specific recommendations by some clinical specialties

\section{Renal recommendation}

11. Adjustments of insulin therapy in diabetic patients

$50 \%$ reduction in long-acting insulin 
Table 3 Therapeutic/preventive care, GRADE level of evidence and strength of recommendation* (Continued)

\begin{tabular}{|c|c|c|}
\hline Recommendation & $\begin{array}{l}\text { Level of } \\
\text { evidence }\end{array}$ & $\begin{array}{l}\text { Strength of } \\
\text { recommendation }\end{array}$ \\
\hline \multicolumn{3}{|l|}{ Cardiovascular recommendations } \\
\hline \multicolumn{3}{|l|}{ 12. Beta-blockers } \\
\hline Continuation of beta-blockers & Low & Weak for \\
\hline For patients with positive test for myocardial ischemia undergoing vascular surgery & Low & Weak for \\
\hline Start the day of surgery treatment regardless of the condition to be treated & High & Strong against \\
\hline \multicolumn{3}{|l|}{ 13. Statins } \\
\hline $\begin{array}{l}\text { Continuation of statins or start before undergoing noncardiac surgery patients with significant } \\
\text { atherosclerosis as secondary prevention }\end{array}$ & Low & Weak for \\
\hline Treatment naïve patients undergoing noncardiac surgery without significant atherosclerosis & Low & Strong against \\
\hline \multicolumn{3}{|l|}{ 14. Aspirin } \\
\hline Suspending aspirin three or more days before noncardiac surgery and not restart within a week after it & High & Strong for \\
\hline $\begin{array}{l}\text { Continuation of aspirin ( } 75-100 \mathrm{mg} \text { daily) in patients who presented acute coronary syndrome in the } \\
\text { last } 12 \text { months or history of percutaneous coronary intervention }\end{array}$ & Low & Weak for \\
\hline Start or not to suspend treatment prior to surgery & High & Strong against \\
\hline \multicolumn{3}{|l|}{ 15. Renin-angiotensin system inhibitors } \\
\hline $\begin{array}{l}\text { Suspend them the day of surgery in chronically medicated patients and restart immediately in } \\
\text { hemodynamically stable conditions }\end{array}$ & Low & Weak for \\
\hline \multicolumn{3}{|l|}{ Start in patients with severe hypertension or ventricular dysfunction if suspending the day of surgery } \\
\hline Start treatment the day of surgery in patients who do not receive it chronically & Low & Strong against \\
\hline \multicolumn{3}{|l|}{ 16. Calcium channel blockers } \\
\hline Suspend the single preoperative dose the day of the surgery in chronically medicated patients & Low & Weak for \\
\hline \multicolumn{3}{|l|}{$\begin{array}{l}\text { Starting treatment in patients with inducible myocardial ischemia or suspected coronary vasospasm } \\
\text { during preoperative evaluation and suspend the single dose the day of surgery }\end{array}$} \\
\hline Starting calcium channel blockers in the preoperative surgery in patients who do not receive chronically & Low & Strong against \\
\hline
\end{tabular}

population or the type of surgery. Out of these recommendations, there were 28 (35.9\%) with a high evidence level, 18 (23.1\%) with a moderate level, 24 (30.8\%) with a low level, and 8 (10.2\%) with a very low level. Regarding their recommendation strengths, 41 (52.6\%) were strong for, $18(23.1 \%)$ were strong against, 14 (17.9\%) weak for, and $5(6.4 \%)$ weak against. In Online supplemental material Appendix 7, we present an additional table concerning antimicrobial prophylaxis recommendations for each surgical site.

We found discrepancies among EB-CPG in 3 out of 78 (4\%) of the therapeutic/preventive care recommendations. After applying the direction and strength of recommendations rule to decide doing or not doing the CPG, 15 (55 specific) recommended and 10 (23 specific) did not recommended therapeutic/preventive interventions (see Online supplemental material Appendix 8, Online supplemental material Appendix 6 - Table 1 GRADE level of evidence and strength of recommendations by CPG; Table 2 Recommended therapeutic/preventive care only, and Table 3 Not recommended therapeutic/preventive care).

\section{Discussion}

To the best of our knowledge, the present study is the first overview of guidelines encompassing a broad spectrum of preoperative care recommendations.

We observed higher level of evidence supporting therapeutic than risk stratification recommendations (high/ moderate quality of evidence 59 vs $22 \%$, respectively). It is not surprising because cross-sectional or cohort studies can provide high-quality evidence for test accuracy but indirect evidence for patient-important outcomes. Furthermore, highs level of heterogeneity is almost the rule in risk stratifications test, downgrading even more the level of evidence because of inconsistency [42-44].

The strength of a recommendation is defined as the extent to which one can be confident that the desirable effects of an intervention outweigh its undesirable ones. We found only $12 / 53$ (23\%) "strong" risk stratification recommendations statements (for and against) based on high/moderate level of evidence and 43/78 (55\%) for therapeutic/preventive care recommendation. Although it would be desirable that higher proportions of high- 
quality supporting evidence guide panel must consider additional factors. In order to assess competing management alternatives, GRADE proposes to consider four domains: estimates of effect for desirable and undesirable outcomes, confidence in the estimates of effect, values and preferences, and resource use. Guideline panels must integrate these factors to make a strong or weak recommendation for or against an intervention [45].

After our search date, the updated guideline from the European Society of Anesthesiology (ESA) was published, using GRADE and searching until May 2016 [46]. This CPG addressed two main clinical questions in order to help each anesthesiologists in their daily practice: (1) how should a pre-operative consultation clinic be organized and (2) how should pre-operative assessment of a patient be performed. As in our present work, this guideline covered specific conditions that might adversely interfere with anesthesia and surgery, including cardiovascular disease, respiratory disease, smoking, obstructive sleep apnea syndrome, renal disease, diabetes, obesity, coagulation disorders, anemia and pre-operative blood conservation strategies, the geriatric patient, alcohol and drug misuse and addiction, and currently also neuromuscular disease. We are hereby presenting a preoperative clinical risk criteria and categories that were complemented with established risk factors for postoperative pulmonary complications (see Online supplemental material Appendix 3) [46]. The 2018 ESA guidelines also provided independent predictors for difficult mask ventilation, a topic not specifically addressed in previous CPGs [46].

As described, RCTs are still few and therefore many preoperative interventions rely to a large extent on expert opinion, which in turn requires to be adapted to the reality of nations' healthcare systems. This large evidence gap should be addressed by related researchers in order to improve the certainty in evidence-based recommendations.

Studies on prognostic or diagnostic accuracy tests, including scoring of severity of illness, usually provide low quality of evidence, even when scores such as ASA-PS, RCRI, NSQIP-MICA, POSSUM, and others have been extensively validated [46].

Our updated overview of EB-CPGs, conducted under the rigorous Cochrane methods, may be a useful resource for the professionals involved in preoperative care to consult during decision-making. We present many strong recommendations with sufficient evidence to be routinely implemented in clinical practice. However, any decision should be taken considering local contextual factors.

In addition, cost reductions were identified at the clinical level as well as at the health system level in another study [10-12, 47]. Two guidelines also suggested strong costs benefits both for patients and society [48, 49]. Another study showed that the application of EB-CPGs significantly improved the efficiency of the preoperative evaluation without negatively affecting the quality of care [50]. These findings were consistent across different settings, like in a hospital in Barbados where the introduction of guidelines reduced the burden of presurgical tests and costs with not hampering patient's safety [51]. In the same way, a recent study in a hospital in New Jersey, USA, found that approximately $25 \%$ of tests were not justifiable and could be thus eliminated by complying with NICE/ ASA guidelines. The evaluation of applying these changes in practice showed significant savings without altering clinical outcomes [52].

Recommendations can be adopted, modified, or even not implemented, depending on institutional or national requirements and legislation and local availability of devices, drugs, and resources [53]. Decision-makers at the national and subnational levels should be provided with the information they need to apply the evidence and recommendations in their setting [54]. As a limitation, including only EB-CPGs could have resulted in omitting some information, but we prioritized summarizing the highest quality evidence. Our exclusion criteria for CPGs, limiting the scope, may represent an additional caveat. Our inclusion/exclusion criteria focused on general recommendations provided a lower amount of evidence for certain practices than if we had also included recommendations for single conditions, specific prophylaxis, or single body part surgeries. Such approach, however, would have compromised the feasibility of our systematic review due to the enormous number of such guidelines. Nonetheless, we provided detailed lists with numerous recommendations and reflected guideline's discrepancies, suggesting that this could not have been a major limitation.

Our study will be useful for future preoperative care guideline developers or adapters. Consistently with other overviews of clinical guidelines, the domain that received the lowest mean score was the "applicability" domain of the AGREE-II tool. Similarly, the heterogeneity of evidence and the strength of recommendation grading systems in this overview echo that of other clinical guideline overviews [55-57]. Low scores in the applicability domain result in inadequate adoption rates of guidelines, particularly for preoperative care where "defensive medicine" (i.e., prescribing more tests than necessary just to prevent litigation) is very common. We also found some discrepancies, mainly in the evidence level, in each recommendation that did not always discriminate between universal interventions and those suitable only for special target groups or specific surgeries.

Guideline developers should ensure rigorous methodological processes and should also make recommendations that are formulated and disseminated in ways that facilitate understanding and application by end-users. For example, 
the DECIDE Collaboration conducted research and developed tools to improve implementation of evidence-based recommendations by different target audiences, including providers, policy makers, and the public [58]. In that sense, GRADE provides guideline developers with a comprehensive and transparent framework for grading quality of evidence and of strength of recommendations.

Our overview identified several controversies, evidence gaps, and issues regarding preoperative care guidelines that warrant future research and reveal opportunities to improve the guidelines quality.

For example, we found many discrepancies about risk stratification recommendations like electrocardiography and chest X-ray, polysomnography, assessment of left ventricular function, stress testing, and coronary angiography in certain populations. We found less discrepancies for therapeutic/ preventive care mainly because antimicrobial prophylaxis use beta-blockers (find these discrepancies in the Online supplemental material Appendix 6 and Appendix 8).

From the perspective of the anesthesiologist practice, there still remain many unanswered questions. For example, in the patient with significant medical, surgical, or obstetrical history, it would be useful to understand how early the pre-anesthetic evaluation should be performed, considering the time required to optimize the patient's status. There are also uncertainties for the recommendation of fasting for solids in adults and children since many factors can delay gastric emptying, and no fixed rules apply. Fasting should be individualized in some patients and depend on the characteristics of the fat intake. Regarding prokinetics and antacids, patients' comorbidities like esophageal pathology, bariatric surgery history, or obesity should be considered in the decision, but there is no formal recommendation. In the same way, suspending or not suspending aspirin should be evaluated according to the patient's history and risk of bleeding of the surgery that could be catastrophic in neurosurgery, spinal surgery, or ophthalmologic surgery. It is also strange that informed consent only has a "weak for," recommendation from a unique CPGs since there is enough background of litigation due to the lack of consent.

We encourage guideline developers to adopt GRADE and AGREE-II tools to elaborate future sound preoperative care guidelines [7, 22].

The huge amount of resources involving preoperative care warrants high-quality nationwide EB-CPGs supported by all relevant stakeholders to improve the chances of a successful implementation. This probably includes the involvement of the Ministry of Health, scientific societies, and consumers working together through a formal process of implementation and monitoring [17, 59].

Although standardization of preoperative care may be desirable, differences in recommendations could reflect
Table 4 Key points

- The included evidence-based clinical practice guidelines (EB-CPGs) showed significant heterogeneity both of evidence and recommendation grading systems; GRADE was the most commonly used.

- About half of the included EB-CPGs were updated in the last 5 years, and one third of them were rated as strongly recommended based in their high AGREE-II performance.

- They were generally deficient in applicability and in providing monitoring tools.

- We summarized 31 risk stratification and 16 therapeutic/preventive recommendations.

- We found 93 strong for and 46 strong against recommendations, all of which were ready to be considered to be implemented or to be interrupted, respectively.

- The level of evidence and strength of recommendation was higher for therapeutic/preventive recommendation than for risk stratification ones.

- We only found 12/53 (55\%) strong risk stratification recommendations based on high/moderate level of evidence and 43/78 (55\%) for therapeutic/preventive care recommendations.

differences in contextual factors such as organizational or financial arrangements, legal framework, varied values and preferences, and the acceptability and feasibility of using different interventions. Research exploring reasons for conflicting recommendations in different countries or settings could also drive overall improvements in guideline quality. The key findings are described in Table 4.

In conclusion we found significant heterogeneity of guidelines' quality and rating systems, as well as deficiencies in several guideline quality domains, which reveal opportunities for quality improvement which deserve careful consideration by future guideline developers. Nevertheless, we present many strong recommendations ready to be at present considered for implementation or discontinuation.

\section{Supplementary information}

Supplementary information accompanies this paper at https://doi.org/10. 1186/s13643-020-01404-8.

Additional file 1. Online Only Supplemental Material.

\section{Abbreviations}

CPG: Clinical practice guidelines; GRADE: Grading of Recommendations Assessment, Development, and Evaluation; HTA: Health Technology Assessment; EB-CPG: Evidence based-clinical practice guidelines; RCT: Randomized clinical trials; Y: Yes; N: No; PY: Probably yes; PN: Probably no; HSTAT: Health services/technology assessment text; NICE: National Institute for Health and Clinical Excellence; ICSI: Institute for Clinical Systems Improvement; ESA: European Society of Anesthesiology; ESC/ESA: European Society of Cardiology/European Society of Anesthesia; SBC: Brazilian Society of Cardiology; ACC/AHA: American College of Cardiology/American Heart Association; CCSG: Canadian Cardiovascular Society; SARNePI: Italian Society of Anesthesia and Intensive Pediatric Therapy and Neonatology; ICSI: Institute for the Improvement of Clinical Systems; BARA: Regional Anesthesia Associations of Belgium; ASHP: American Society of Health-System Pharmacists; SIGN: Scottish Intercollegiate Guidelines Network; SAC: Argentine Society of Cardiology; EROS: Early Review Organizing Software 


\section{Acknowledgements}

We acknowledge Dr. Claudio Isod, Anesthesiologist and member of the Sociedad Platense de Anestesiología, for his valuable feedback and Dr. Juan Manuel Rey, Anesthesiologist, for his valuable feedback.

\section{Authors' contributions}

A.C and A.B. provided substantial contribution to the conception and design, E.T.L and S.A.V undertook the acquisition of data. All authors contributed to the analysis and interpretation of data; drafting the article or revising it critically for important intellectual content, and provided final approval of the final version submitted.

\section{Funding}

Independent grant of the Argentine Federation of Associations of

Anesthesia, Analgesia and Resuscitation (FAAAAR)

\section{Availability of data and materials}

Not applicable.

\section{Ethics approval and consent to participate}

Not applicable.

\section{Consent for publication}

Not applicable.

\section{Competing interests}

None.

Received: 23 January 2020 Accepted: 1 June 2020

Published online: 13 July 2020

\section{References}

1. Weiser TG, Regenbogen SE, Thompson KD, Haynes AB, Lipsitz SR, Berry WR, et al. An estimation of the global volume of surgery: a modelling strategy based on available data. Lancet. 2008:372(9633):139-44. https://doi.org/10. 1016/S0140-6736(08)60878-8.

2. Uribe-Leitz T, Esquivel MM, Molina G, Lipsitz SR, Verguet S, Rose J, et al. Projections for achieving the lancet commission recommended surgical rate of 5000 operations per 100,000 population by region-specific surgical rate estimates. World J Surg. 2015;39(9):2168-72. https://doi.org/10.1007/s00268015-3113-6 Epub 2015/06/13. PubMed PMID: 26067635

3. Siddiqui NF, Coca SG, Devereaux PJ, Jain AK, Li L, Luo J, et al. Secular trends in acute dialysis after elective major surgery--1995 to 2009. CMAJ. 2012; 184(11):1237-45. https://doi.org/10.1503/cmaj.110895 PubMed PMID: 22733671; PubMed Central PMCID: PMCPMC3414596.

4. Botto F, Alonso-Coello P, Chan MT, Villar JC, Xavier D, Srinathan S, et al. Myocardial injury after noncardiac surgery: a large, international, prospective cohort study establishing diagnostic criteria, characteristics, predictors, and 30-day outcomes. Anesthesiology. 2014;120(3):564-78. https://doi.org/10. 1097/ALN.0000000000000113 PubMed PMID: 24534856.

5. Devereaux PJ, Xavier D, Pogue J, Guyatt G, Sigamani A, Garutti I, et al. Characteristics and short-term prognosis of perioperative myocardial infarction in patients undergoing noncardiac surgery: a cohort study. Ann Intern Med. 2011;154(8):523-8. https://doi.org/10.7326/0003-4819-154-8201104190-00003 Epub 2011/04/20. PubMed PMID: 21502650

6. Field M, Lohr K. Institute of Medicine. Committee on clinical practice guidelines. Division of health care services. Guidelines for clinical practice: from development to use. Washington: National Academy Press; 1992.

7. Guyatt G, Oxman AD, Akl EA, Kunz R, Vist G, Brozek J, et al. GRADE guidelines: 1. Introduction-GRADE evidence profiles and summary of findings tables. J Clin Epidemiol. 2011;64(4):383-94. https://doi.org/10.1016/j. jclinepi.2010.04.026 Epub 2011/01/05. PubMed PMID: 21195583.

8. Johansson T, Fritsch G, Flamm M, Hansbauer B, Bachofner N, Mann E, et al. Effectiveness of non-cardiac preoperative testing in non-cardiac elective surgery: a systematic review. BJA. 2013;1 10(6):926-39. https://doi.org/10. 1093/bja/aet071.

9. Larocque BJ, Maykut RJ. Implementation of guidelines for preoperative laboratory investigations in patients scheduled to undergo elective surgery. Can J Surg. 1994;37(5):397-401 PubMed PMID: 7922901.
10. Mancuso CA. Impact of new guidelines on physicians' ordering of preoperative tests. J Gen Intern Med. 1999;14(3):166-72 PubMed PMID: 10203622; PubMed Central PMCID: PMCPMC1496555.

11. Nardella A, Pechet L, Snyder LM. Continuous improvement, quality control, and cost containment in clinical laboratory testing. Effects of establishing and implementing guidelines for preoperative tests. Arch Pathol Lab Med. 1995;119(6):518-22 PubMed PMID: 7605167.

12. Power $L M$, Thackray NM. Reduction of preoperative investigations with the introduction of an anaesthetist-led preoperative assessment clinic. Anaesth Intensive Care. 1999;27(5):481-8 PubMed PMID: 10520388.

13. Roizen MF. Cost-effective preoperative laboratory testing. JAMA. 1994;271(4): 319-20 PubMed PMID: 8295297.

14. Arvidsson S, Bjork L, Brorsson B, Haglund U, Jorfeldt L, Lundberg D, et al. Preoperative routines. Stockholm: The Swedish Council on Technology Assessment in Health Care (SBU); 1989.

15. Arnaez R, Arana J, Asua J, Gutierrez M, Baile M. Healthy/asymptomatic patient preoperative evaluation - nonsystematic review, expert panel, guidelines. 94. Vitoria-Gasteiz: OSTEBA (Basque Office for Health Technology Assessment, Health Department of the Basque Government).

16. Higgins J, Green S, (editors). Cochrane handbook for systematic reviews of interventions version 5.1.0 [updated March 2011]. 2011. Available from www.cochrane-handbook.org.

17. Guía para la adaptación de Guías de Práctica Clínica. Instituto de Investigaciones Epidemiológicas, Academia Nacional de Medicina. 2008.

18. Moher D, Liberati A, Tetzlaff J, Altman DG. Preferred reporting items for systematic reviews and meta-analyses: the PRISMA statement. PLoS Med. 2009;6(7):e1000097. https://doi.org/10.1371/journal.pmed.1000097 Epub 2009/07/22. PubMed PMID: 19621072.

19. Bougioukas KI, Liakos A, Tsapas A, Ntzani E, Haidich AB. Preferred reporting items for overviews of systematic reviews including harms checklist: a pilot tool to be used for balanced reporting of benefits and harms. J Clin Epidemiol. 2017. https://doi.org/10.1016/j.jclinepi.2017.10.002 PubMed PMID: 29037888

20. García Gutiérrez JF, Bravo TR. Guías de práctica clínica en Internet Atención Primaria. 2001;28(1):74-9. https://doi.org/10.1016/s02126567(01)78899-3.

21. Glujovsky D, Bardach A, García Martí S, Comandé D, Ciapponi A. EROS: a new software for early stage of systematic reviews. Value Health. 2011;14(7): A564. https://doi.org/10.1016/j.jval.2011.08.1689.

22. Brouwers MC, Kho ME, Browman GP, Burgers JS, Cluzeau F, Feder G, et al. AGREE II: advancing guideline development, reporting and evaluation in health care. CMAJ. 2010;182(18):E839-42. https://doi.org/10.1503/cmaj. 090449 PubMed PMID: 20603348; PubMed Central PMCID: PMCPMC3001530

23. Urrea JK, Yela Muñoz IE, Cifuentes C. Valoración perioperatoria del paciente para cirugía no cardiaca. Rev Colom Cardiol. 2015;22(5):235-43. https://doi. org/10.1016/j.rccar.2015.02.007.

24. Guía de Práctic Clínica. Valoración perioperatoria en cirugía no cardiaca en el adulto. Evidencias y Recomendaciones. 2010.

25. NICE. National Institute for health and care excellence: clinical guidelines. Preoperative tests (update): routine preoperative tests for elective surgery. London: National Institute for Health and Care Excellence: Clinical Guidelines; 2016.

26. Kristensen SD, Knuuti J, Saraste A, Anker S, Botker HE, De Hert S, et al. 2014 ESC/ESA guidelines on non-cardiac surgery: cardiovascular assessment and management: the joint task force on non-cardiac surgery: cardiovascular assessment and management of the European Society of Cardiology (ESC) and the European Society of Anaesthesiology (ESA). Eur J Anaesthesiol. 2014:31(10):517-73. https://doi.org/10.1097/eja.0000000000000150 Epub 2014/08/16. PubMed PMID: 25127426

27. Gualandro DM, Yu PC, Caramelli B, Marques AC, Calderaro D, Fornari LS, et al. 3rd guideline for perioperative cardiovascular evaluation of the Brazilian Society of Cardiology. Arq Bras Cardiol. 2017;109:1-104.

28. Fleisher LA, Fleischmann KE, Auerbach AD, Barnason SA, Beckman JA, Bozkurt B, et al. 2014 ACC/AHA guideline on perioperative cardiovascular evaluation and management of patients undergoing noncardiac surgery: executive summary: a report of the American College of Cardiology/American Heart Association Task Force on Practice Guidelines. Circulation. 2014;24:221545. https://doi.org/10.1161/cir.0000000000000105 PubMed PMID: 2029.

29. Duceppe E, Parlow J, MacDonald P, Lyons K, McMullen M, Srinathan S, et al. Canadian cardiovascular society guidelines on perioperative cardiac risk 
assessment and management for patients who undergo noncardiac surgery. Can J Cardiol. 2017;1:17-32. https://doi.org/10.1016/j.cjca.2016.09. 008 PubMed PMID: 281.

30. Nygren J, Thacker J, Carli F, Fearon KCH, Norderval S, Lobo DN, et al. Guidelines for perioperative care in elective rectal/pelvic surgery: enhanced recovery after surgery (ERAS\&Acirc;\&reg;) society recommendations. Clin Nutr. 2012;6:801-16. https://doi.org/10.1016/j.clnu.2012.08.012 PubMed PMID: 918.

31. Serafini $G$, Ingelmo PM, Astuto M, Baroncini S, Borrometi F, Bortone $L$, et al Preoperative evaluation in infants and children: recommendations of the Italian Society of Pediatric and Neonatal Anesthesia and Intensive Care (SARNePI). Minerva Anestesiol. 2014;4:461-9 PubMed PMID: 2119.

32. Danielson D, Bjork K, Card R, Foreman J, Harper C, Roemer R, et al. Health care guideline: preoperative evaluation. 2012. PubMed PMID: 1.

33. Nelson G, Altman AD, Nick A, Meyer LA, Ramirez PT, Achtari C, et al. Guidelines for pre- and intra-operative care in gynecologic/oncology surgery: enhanced recovery after surgery (ERAS) society recommendations part i. Gynecol Oncol. 2016;2:313-22. https://doi.org/10.1016/j.ygyno.2015.11. 015 PubMed PMID: 429.

34. Smith I, Kranke P, Murat I, Smith A, Sullivan G, Soreide E, et al. Perioperative fasting in adults and children: guidelines from the European Society of Anaesthesiology. Eur J Anaesthesiol. 2011;8:556-69. https://doi.org/10.1097/ EJA.0b013e3283495ba1 PubMed PMID: 2298

35. Van De Velde M, Vercauteren M, Stockman W, Roelants F, Coppens M, Bauters $\mathrm{M}$, et al. Recommendations and guidelines for obstetric anesthesia in Belgium. Acta Anaesthesiol Belg. 2013;3:97-104 PubMed PMID: 2115.

36. Bratzler DW, Dellinger EP, Olsen KM, Perl TM, Auwaerter PG, Bolon MK, et al. Clinical practice guidelines for antimicrobial prophylaxis in surgery. Am J Health Syst Pharm. 2013;70(3):195-283. https://doi.org/10.2146/ajhp120568 PubMed PMID: 23327981

37. SIGN. Antibiotic prophylaxis in surgery a national clinical guideline. Edinburgh: Scottish Intercollegiate Guidelines Network (SIGN); 2014. [12/1/ 2017]. Available from: http://www.sign.ac.uk/assets/sign104.pdf.

38. Berrios-Torres SI, Umscheid CA, Bratzler DW, Leas B, Stone EC, Kelz RR, et al. Centers for disease control and prevention guideline for the prevention of surgical site infection, 2017. JAMA Surg. 2017:8:784-91. https://doi.org/10. 1001/jamasurg.2017.0904 PubMed PMID: 2.

39. Calise F, Capussotti L, Caterino S, Delitala A, Terrazzi P, Francucci M, et al. Perioperative antibiotic prophylaxis in adults. Outline of the principal recommendations. National reference guidelines. Minerva Anestesiol. 2009; 75(9):543-7, 8-52 PubMed PMID: 19644438.

40. Krauss J. Consenso Argentino de Evaluación de Riesgo Cardiovascular en Cirugía No Cardíaca. Rev Argent Cardiol. 2016;86(Suplemento 1):166-83.

41. SIGN 50: a guideline developer's handbook: Scottish Intercollegiate Guidelines Network; 2008 [01/18/2018]. Available from: www.sign.ac.uk/ guidelines/fulltext/50/index.html.

42. Singh S, Chang SM, Matchar DB, Bass EB. Grading a body of evidence on diagnostic tests. In: Chang SM, Matchar DB, Smetana GW, Umscheid CA, editors. Methods guide for medical test reviews. Rockville: AHRQ Methods for Effective Health Care; 2012.

43. Hsu J, Brożek JL, Terracciano L, Kreis J, Compalati E, Stein AT, et al. Application of GRADE: making evidence-based recommendations about diagnostic tests in clinical practice guidelines. Implement Sci. 2011;6(1):1-9. https://doi.org/10.1186/1748-5908-6-62.

44. Schünemann HJ, Oxman AD, Brozek J, Glasziou P, Jaeschke R, Vist GE, et al, Grading quality of evidence and strength of recommendations for diagnostic tests and strategies. BMJ. 2008;336(7653):1106-10.

45. Andrews JC, Schunemann HJ, Oxman AD, Pottie K, Meerpohl JJ, Coello PA, et al. GRADE guidelines: 15. Going from evidence to recommendationdeterminants of a recommendation's direction and strength. J Clin Epidemiol. 2013;66(7):726-35. https://doi.org/10.1016/j.jclinepi.2013.02.003 PubMed PMID: 23570745

46. De Hert S, Staender S, Fritsch G, Hinkelbein J, Afshari A, Bettelli G, et al. Preoperative evaluation of adults undergoing elective noncardiac surgery: updated guideline from the European Society of Anaesthesiology. Eur J Anaesthesiol. 2018;35(6):407-65. https://doi.org/10.1097/eja. 0000000000000817 PubMed PMID: 00003643-201806000-00002

47. France $\mathrm{FH}$, Lefebvre $\mathrm{C}$. Cost-effectiveness of preoperative examinations. Acta Clin Belg. 1997;52(5):275-86 PubMed PMID: 9489121.
48. (SBU). SCOTAiHC. Preoperative Routines Stockholm 1989. Available from: http://www.sbu.se/en/publications/sbu-assesses/preoperativeroutines/2 $0 / 11 / 2017$.

49. Lopez-Bastida J, Serrano-Aguilar P, Duque-Gonzalez B, et al. [Cost analysis and potential savings related to the use of preoperative tests in the hospitals of the Canary Islands [Spain]]. Gac Sanit 2003;17(2):131-6.

50. Ferrando A, Ivaldi C, Buttiglieri A, Pagano E, Bonetto C, Arione R, et al. Guidelines for preoperative assessment: impact on clinical practice and costs. Int J Qual Health Care. 2005;17(4):323-9. https://doi.org/10.1093/ intahc/mzi039 PubMed PMID: 15831541.

51. Nicholls J, Gaskin PS, Ward J, Areti YK. Guidelines for preoperative investigations for elective surgery at Queen Elizabeth Hospital: effects on practices, outcomes, and costs. J Clin Anesth. 2016;35:176-89. https://doi. org/10.1016/j.jclinane.2016.07.008 PubMed PMID: 27871517.

52. Gupta S. Financial impact of applying modified NICE/ASA guidelines to current practice for preoperative testing. Boston: Anesthesiology 2017 from the American Society of Anesthesiologists; October 23, 2017; 2017. p. A2168.

53. Schunemann HJ, Wiercioch W, Brozek J, Etxeandia-Ikobaltzeta I, Mustafa RA, Manja V, et al. GRADE evidence to decision (EtD) frameworks for adoption, adaptation, and de novo development of trustworthy recommendations: GRADE-ADOLOPMENT. J Clin Epidemiol. 2017;81:101-10. https://doi.org/10. 1016/j.jclinepi.2016.09.009 PubMed PMID: 27713072.

54. WHO. WHO Handbook for Guideline Development. Ginebra: World Health Organization; 2014. [12/10/2018]. Available from: http://apps.who.int/ medicinedocs/documents/s22083en/s22083en.pdf.

55. Pillastrini P, Gardenghi I, Bonetti F, Capra F, Guccione A, Mugnai R, et al. An updated overview of clinical guidelines for chronic low back pain management in primary care. Joint Bone Spine. 2012;79(2):176-85. https:// doi.org/10.1016/j.jbspin.2011.03.019 PubMed PMID: 21565540.

56. Miller S, Abalos E, Chamillard M, Ciapponi A, Colaci D, Comande D, et al. Beyond too little, too late and too much, too soon: a pathway towards evidence-based, respectful maternity care worldwide. Lancet. 2016. https:// doi.org/10.1016/S0140-6736(16)31472-6 PubMed PMID: 27642019.

57. Lambert E, Carey S. Practice guideline recommendations on perioperative fasting: a systematic review. JPEN J Parenter Enteral Nutr. 2016;40(8):115865. https://doi.org/10.1177/0148607114567713 PubMed PMID: 25575497.

58. Treweek S, Oxman AD, Alderson P, Bossuyt PM, Brandt L, Brozek J, et al. Developing and evaluating communication strategies to support informed decisions and practice based on evidence (DECIDE): protocol and preliminary results. Implement Sci. 2013;8:6. https://doi.org/10.1186/17485908-8-6 PubMed PMID: 23302501: PubMed Central PMCID. PMCPMC3553065.

59. Darzi A, Abou-Jaoude EA, Agarwal A, Lakis C, Wiercioch W, Santesso N, et al. A methodological survey identified eight proposed frameworks for the adaptation of health related quidelines. J Clin Epidemiol. 2017:86:3-10. https://doi.org/10.1016/j.jclinepi.2017.01.016 PubMed PMID: 28412463.

\section{Publisher's Note}

Springer Nature remains neutral with regard to jurisdictional claims in published maps and institutional affiliations.

Ready to submit your research? Choose BMC and benefit from:

- fast, convenient online submission

- thorough peer review by experienced researchers in your field

- rapid publication on acceptance

- support for research data, including large and complex data types

- gold Open Access which fosters wider collaboration and increased citations

- maximum visibility for your research: over $100 \mathrm{M}$ website views per year

At $\mathrm{BMC}$, research is always in progress.

Learn more biomedcentral.com/submissions 